\title{
Long Term Observation of Atmospheric Aerosols at Sakai, Osaka, Japan
}

\author{
Norio Ito*, Akira Mizohata \\ Frontier Science Innovation Center, Osaka Prefecture University, Japan
}

\begin{abstract}
We have continuously observed the aerosols with 3 kinds of samplers; automatic daily sampler (DS), Andersen sampler (AS) and Low pressure Andersen Sampler (LPAS) at Sakai, Osaka, Japan. We started these sampling from 1986 (DS), 1993 (AS) and 2000 (LPAS). Yearly mean of fine particles $(<2.1 \mu \mathrm{m})$ has decreased by about $10 \mu \mathrm{g} / \mathrm{m}^{3}$ from 1993 to 2009 . By contrast the coarse particles $(>2.1 \mu \mathrm{m})$ do not have explicit decrease. The main constituents in fine particles are carbon matters (EC and OC) and ions (sulphate and nitrate). Ions do not have decrease trend. These trends indicate that the decrease of fine particles might be caused by the decrease of carbon matters.
\end{abstract}

The atmospheric aerosols affect the global climate and its fine particle that are exposed to our body cause the disease. The concentrations of atmospheric aerosols change yearly, seasonally and daily. So, to understand the change in aerosols, we have observed the atmospheric aerosols at Sakai, Osaka. We have analyzed its constituents (ions, elements, elemental and organic carbon) in the aerosols to reveal the affect of aerosols to the climate and our health. In this report we show the method of sampling and analysis and the yearly change in mass concentrations of fine and coarse aerosols.

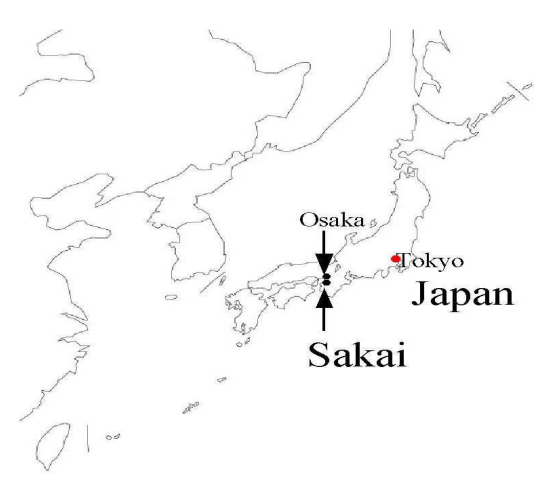

Location of Sakai

We have continuously observed the aerosols with 3 kinds of samplers, automatic daily sampler, Andersen sampler and Low pressure (LP) Andersen sampler at Sakai in Osaka Prefecture. Sakai city is in the south of Osaka City, the second biggest city in Japan and the population is about 2.7 million and the population of Sakai City is about 0.8 million. The industry area is about $10 \mathrm{~km}$ west to our sampling station. The particle separation condition, using filter and sampling period 
for the each sampler are listed on Table1. We started these sampling from 1986 using Automatic daily sampler, 1993 using Andersen sampler and 2000 using LP Andersen Sample. We analyzed the constituents in some of the samples. The elements and its analysis method are listed on Table 2 .

Table 1: Sampling method of atmospheric aerosols

\begin{tabular}{|l|l|l|l|}
\hline \multicolumn{1}{|c|}{ Sampler } & \multicolumn{1}{c|}{ Particle separation } & \multicolumn{1}{c|}{ Filter } & \multicolumn{1}{c|}{ Period } \\
\hline Automatic daily & No separation & M, Q & Daily \\
\hline Andersen & 9 ranges & P, TB, Q & One week \\
\hline LP Andersen & 13 ranges & P, TB, Q & 2 weeks \\
\hline
\end{tabular}

Filter M: Membrane, P:Polyethylene, Q:Quartz, TB: Teflon for backup

Table 2: Analytical method of constituents

\begin{tabular}{|l|l|}
\hline \multicolumn{1}{|c|}{ Constituents } & \multicolumn{1}{|c|}{ Method } \\
\hline Ions: $\mathrm{Cl}-, \mathrm{NO} 3-, \mathrm{SO} 42-, \mathrm{Na}+, \mathrm{NH} 4+, \mathrm{K}+, \mathrm{Mg} 2+$, & Ion chromatography \\
\hline $\mathrm{Al}, \mathrm{Si}, \mathrm{S}, \mathrm{Cl}, \mathrm{K}, \mathrm{Ca}, \mathrm{Ti}, \mathrm{V}, \mathrm{Cr}, \mathrm{Mn}, \mathrm{Fe}, \mathrm{Cu}, \mathrm{Zn}, \mathrm{Pb}$ & X-ray fluorescence \\
\hline $\begin{array}{l}\mathrm{Na}, \mathrm{Al}, \mathrm{Cl}, \mathrm{K}, \mathrm{Ca}, \mathrm{Sc}, \mathrm{Ti}, \mathrm{V}, \mathrm{Cr}, \mathrm{Mn}, \mathrm{Fe}, \mathrm{Co}, \mathrm{Ni}, \\
\mathrm{Cu}, \mathrm{Zn}, \mathrm{As}, \mathrm{Se}, \mathrm{Br}, \mathrm{Rb}, \mathrm{Y}, \mathrm{Mo}, \mathrm{Ag}, \mathrm{Cd}, \mathrm{Sb}, \mathrm{Cs}, \\
\mathrm{Ba}, \mathrm{La}, \mathrm{Ce}, \mathrm{Sm}, \mathrm{Eu}, \mathrm{Hf}, \mathrm{Ta}, \mathrm{W}, \mathrm{Au}, \mathrm{Hg}, \mathrm{Th}, \mathrm{U}\end{array}$ & \\
\hline Organic and Elemental Carbon & Optical Thermal \\
\hline
\end{tabular}

Yearly mean concentrations of aerosol concentrations of fine $(<2.1 \mu \mathrm{m})$ and coarse particles $(>2.1 \mu \mathrm{m})$ which were observed with Andersen sampler are shown on Fig.1. Yearly mean of fine particles has decreased by about $10 \mu \mathrm{g} / \mathrm{m}^{3}$ from 1993 to 2009. By contrast the coarse particles do not have explicit decrease. The decrease of fine particles might have been caused by the air pollution control.

Ions in the aerosols that have been collected daily on the quartz filter were analyzed with ion chromatography. We have yearly and seasonally change results from 1986 to 2009. In this result $\mathrm{Cl}^{-}$has the explicit decrease from 1996. This was effect of control for waste incinerator reducing gaseous $\mathrm{Cl}$ in the exhaust gas. Gaseous $\mathrm{Cl}$ can be changed to particles $\left(\mathrm{NH}_{4} \mathrm{Cl}\right)$ mainly in winter. On the other hand nitrate and sulfate have not had clearly decrease trend. Especially sulfate might be effect of secondary product sulfate from $\mathrm{SO}_{2}$ emitted in China, going up its emission. Fine particles consist of mainly carbon matter (elementary and organic carbon) and ions $\left(\mathrm{Cl}^{-}, \mathrm{NO}_{3}^{-}\right.$, $\mathrm{SO}_{4}{ }^{2-}, \mathrm{Na}^{+}, \mathrm{NH}_{4}{ }^{+}, \mathrm{K}^{+}, \mathrm{Mg}^{2+}, \mathrm{Ca}^{2+}$ ). Carbon matter might be mainly affected from the particles in diesel exhaust gas. Japan government has controlled the vehicle exhaust gas and particles. We guess that this control make the fine particle concentration have the recent decrease trend. 


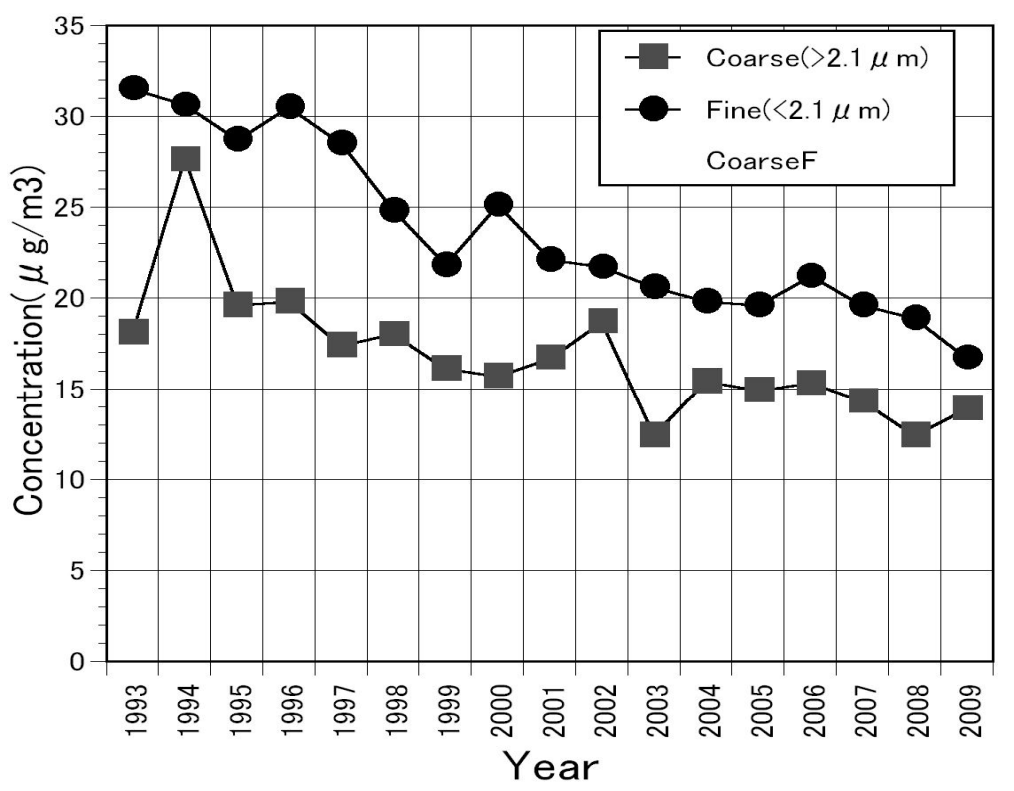

Figure 1: Yearly change in mean mass concentration of coarse $(>2.1 \mu \mathrm{m})$ and fine $(<2.1 \mu \mathrm{m})$ particles observed at Sakai, City from 1993 to 2009
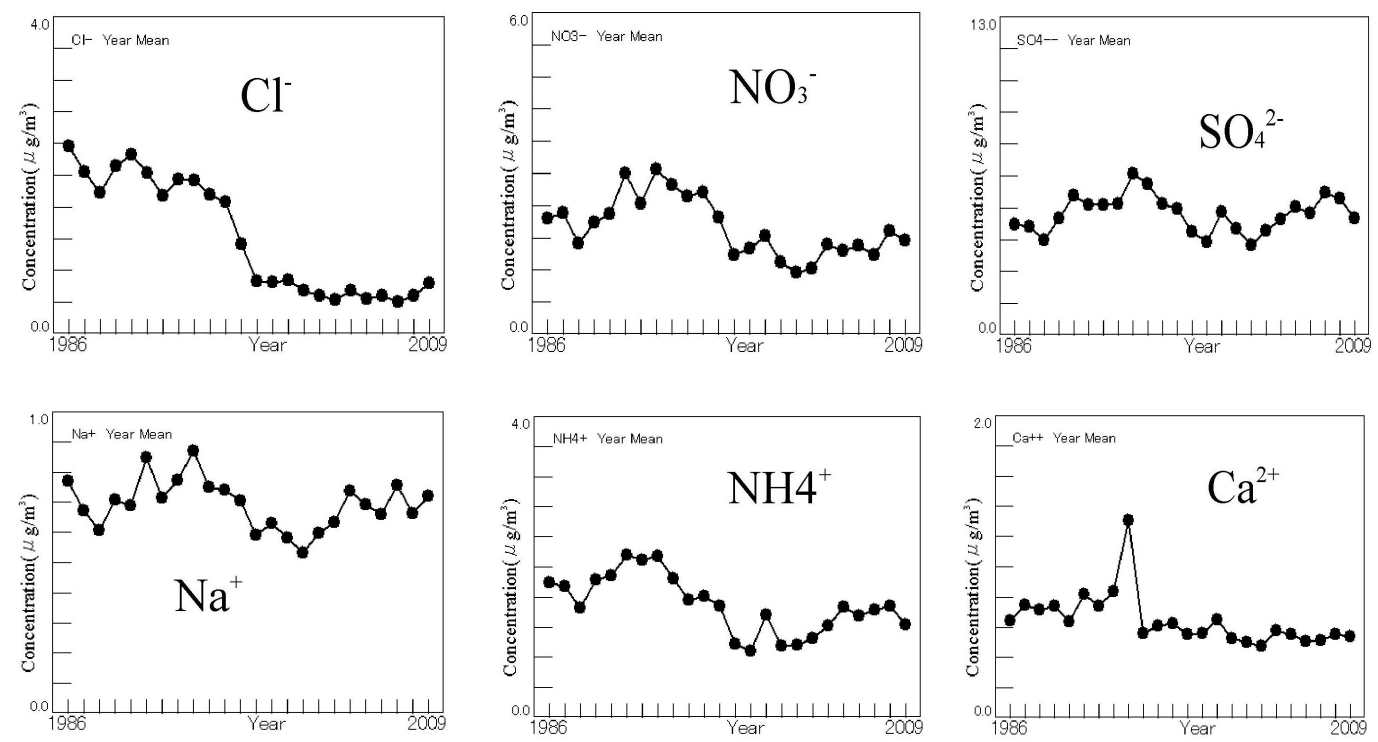

Figure 2: Change in yearly mean of ions in the aerosols daily collected at Sakai, Osaka from 1986 to 2009 